
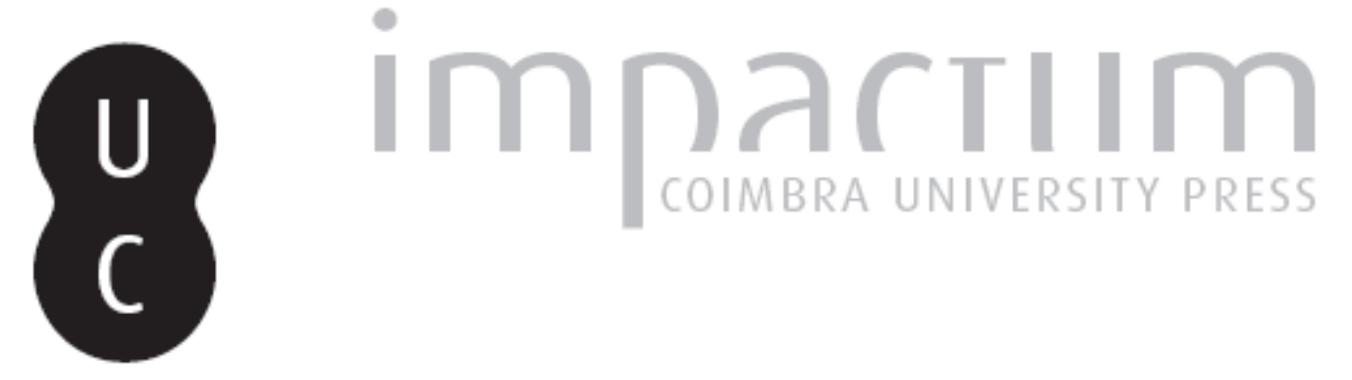

\title{
La donna è mobile...: tradução e comentário do poema alfabético acerca da maldade deminina (Canticum alphabeticum de Mala Muliere, anónimo, século XIII)
}
Autor(es):
Dias, Paula Barata

Publicado por: Imprensa da Universidade de Coimbra

URL persistente:

URI:http://hdl.handle.net/10316.2/37532

DOI:

DOI:http://dx.doi.org/10.14195/0872-2110_59_8

Accessed : $\quad$ 26-Apr-2023 12:28:21

A navegação consulta e descarregamento dos títulos inseridos nas Bibliotecas Digitais UC Digitalis, UC Pombalina e UC Impactum, pressupõem a aceitação plena e sem reservas dos Termos e Condições de Uso destas Bibliotecas Digitais, disponíveis em https://digitalis.uc.pt/pt-pt/termos.

Conforme exposto nos referidos Termos e Condições de Uso, o descarregamento de títulos de acesso restrito requer uma licença válida de autorização devendo o utilizador aceder ao(s) documento(s) a partir de um endereço de IP da instituição detentora da supramencionada licença.

Ao utilizador é apenas permitido o descarregamento para uso pessoal, pelo que o emprego do(s) título(s) descarregado(s) para outro fim, designadamente comercial, carece de autorização do respetivo autor ou editor da obra.

Na medida em que todas as obras da UC Digitalis se encontram protegidas pelo Código do Direito de Autor e Direitos Conexos e demais legislação aplicável, toda a cópia, parcial ou total, deste documento, nos casos em que é legalmente admitida, deverá conter ou fazer-se acompanhar por este aviso.

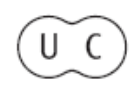


COIMBRA • 2014

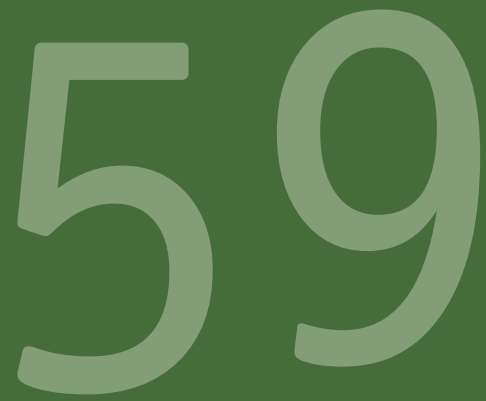

\title{
BOLETIM DE
}

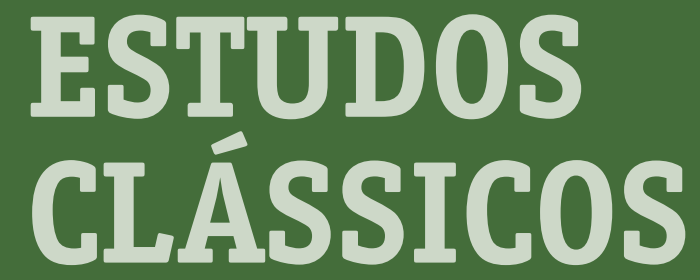

\author{
ASSOCIAÇÃO \\ PORTUGUESA \\ DE ESTUDOS \\ CLÁSSICOS \\ INSTITUTO \\ DE ESTUDOS \\ CLÁSSICOS
}




\section{LA DONNA È MOBILE...:}

TRADUÇÃO E COMENTÁRIO DO

POEMA ALFABÉTICO ACERCA DA

MALDADE FEMININA (CANTICUM

ALPHABETICUM DE MALA MULIERE, ANÓNIMO, SÉCULO XIII) ${ }^{1}$

(LA DONNA È MOBILE...: PORTUGUESE VERSION AND

COMMENTARY OF THE ALPHABETICAL POEM ABOUT THE

WICKEDNESS OF WOMEN (CANTICUM ALPHABETICUM DE MALA

MULIERE, ANONYM, XIII C.E.)

PAULA BARATA DIAS

UC-CECH

Resumo: O tema da misoginia é um tópico literário frequente em toda a literatura latina, antiga e medieval. Apresenta-se uma tradução portuguesa e um comentário literário do Poema alfabético De Mala Muliere, anónimo composto no século XIII, texto que desenvolve o assunto da misoginia recorrendo à antiga tópica anti-feminina, renovada com os novos argumentos do cristianismo desenvolvidos de acordo com o contexto histórico da reforma gregoriana.

1 Puig Rodríguez-Escalona, M., (1995), Poesía Misógina en la Edad Media Latina, Universidad de Barcelona, 40-43. 
Palavras-Chave: Poema Alfabético, Misoginia, Cristianismo, Literatura Latina Medieval, Papa Gregório VII

\begin{abstract}
The theme of misogyny is a frequent literary topic throughout ancient and Medieval Latin literature. It's our aim to propose a Portuguese version and a literary review of the Alphabetical Poem De Mala Muliere, an anonymous thirteenth-century text that develops the subject of female wickedness using not only the ancient anti-female topics, but also new arguments of Christian thinking adapted to the historical context of the Gregorian reform in Western Europe.
\end{abstract}

Keywords: Alphabetical Poem; Misogyny, Christianity, Medieval Latin Literature, Pope Gregory VII

Desde Pandora (Hesíodo, Teog. 590-593; Erg. 60-105) a Eva (Gen. 3) a mulher carrega o fardo de ter trazido o mal ao mundo. Assim, os tópicos literários misóginos apresentam uma larguíssima e sólida tradição na cultura literária antiga, grega e romana, atravessando épocas, autores e géneros literários distintos. Com maior ou menor sentido de humor, com recurso a caricaturas de momentos do quotidiano considerados como fazendo parte do mundo do género feminino, a literatura antiga, sobretudo a que presumia um destinatário mais popular e vasto, é pródiga na censura às mulheres. Lembremo-nos de Aristófanes, e das suas comédias As mulheres na Assembleia ou As Mulheres que Celebram as Tesmofórias, de Plauto, com as suas composições de idosas e alcoviteiras em 0 Truculento e na Comédia da Marmita; da Sátira VI de Juvenal, em que o Poeta apresenta as razões por que um homem do seu tempo deve evitar o casamento, na verdade um catálogo de vícios femininos, que granjeou forte tradição na literatura ocidental posterior.

Um dos primeiros poetas desta mesma tradição, Hesíodo, na sua obra Teogonia, apresenta Pandora, a mulher portadora de todos os dons, mas na verdade um presente envenenado de Zeus à humanidade, agastado que estava pela desobediência de Prometeu. A partir da curiosidade inconse- 
quente de Pandora, semearam-se entre os homens todos os infortúnios que desde então os atingem: discórdia, doenças, fome. O Poeta do séc. VIII a. C. estendeu o julgamento de Pandora ao de todo o seu género, lamentando a sorte do pobre homem a quem só resta discernir sobre o menor dos males: escolher uma mulher que, para si, seja o menos nefasta possível.

A tradição cristã não trouxe consigo alterações significativas ao estatuto do género feminino. A novidade evangélica abriu portas para a maior participação e visibilidade das mulheres, dando contas de uma realidade em que estas eram também chamadas a escutar a revelação e sujeitos dos milagres de Cristo (vejam-se as personagens Maria de Nazaré, Mãe de Jesus; Marta e Maria, irmãs de Lázaro; Joana e Susana; (Lc 8, 3) Maria Madalena, a Samaritana; a Hemorroíssa; a filha do centurião; Verónica). Apesar de S. Paulo ter proclamado o princípio da igualdade entre todos os homens, quaisquer que fossem as suas especificidades de pátria, condição social ou género (Gal. 3, 26-28 "Não há Judeu nem Grego, escravo ou livre, homem ou mulher, pois todos sois um em Cristo"), não é possível, cremos nós, negar que este elevar da consideração pública da mulher esteve confinado a um período inicial do cristianismo, que podemos identificar com o momento em que esta religião e forma de conceber o mundo era minoritária e perseguida.

Apesar disso, os estudiosos apontam, com justiça, a probabilidade de uma elevada proporção de mulheres entre os aderentes à nova fé, e a popularidade desta entre o sexo feminino, em particular em ambiente romano, por razões mais contextuais do que teológicas.

A maior parte das assembleias cristãs reunia-se em casas particulares, no espaço doméstico das famílias cristianizadas. Por isso, as mulheres foram importantes na difusão do cristianismo: educadoras dos primeiros anos de vida das crianças; senhoras do espaço doméstico, onde o braço dos perseguidores não entrava. A elas cabia assegurar a continuidade das gerações de cristãos já nascidos em famílias cristãs. Este é um facto que pode sustentar uma das razões da resiliência do cristianismo, apesar do esforço das autoridades oficiais no seu combate entre o séc. I e IV: 
ainda que os líderes das comunidades, bispos, padres, pastores, e muitos cristãos leigos tivessem sido martirizados, sobreviviam-lhes as mães, as irmãs, as filhas, as mulheres, que passavam quase incólumes à oportunidade de se denunciarem no espaço público, como cristãs, pois não eram sujeitos de impostos nem eram chamadas ao serviço cívico ou militar.

Contudo, Paulo não previu, para a mulher, idêntica tarefa à dos homens na condução das comunidades cristãs, como se pode verificar pela 1Tim 2, 12: as mulheres não devem ensinar, nem deter autoridade sobre o homem, mas que permaneçam em silêncio... ${ }^{2}$.

Uma vez reunidas as condições para que a Igreja se afirmasse legalmente no Século, os novos tempos continuam a estrutura fundamental da mentalidade grega e romana. Criadas as condições para o fortalecimento das instituições e da hierarquia cristã no espaço público, este será ocupado pelos homens. De certo modo, restauraram-se as condições que reservavam para as mulheres o espaço doméstico e o silêncio, sendo de facto este um aspeto do mundo antigo greco-romano a não experimentar a revolução de mentalidades propalada pelo cristianismo.

Portanto, as mulheres são o que delas se diz, uma vez que são muito escassas as vozes em primeira mão, autónomas, das mulheres. Apesar disso, é na Antiguidade Tardia cristã e Idade Média que se encontram vozes literárias femininas, com Egéria, Proba, Duoda, Rosvita de Gandesheim, Catarina de Siena, Hildegarda de Bingen, entre outras, a deixarem os frutos do seu labor intelectual e literário. Contudo, com a exceção de Cristina de Pisano, já no séc. XIV, não se encontra nos escritos destas nenhum apetite pela autoconsciência ou uma crítica quanto às conceções tradicionais de género. Se elas se interrogavam sobre as condições do seu estatuto, é algo que permanece um mistério, se tivermos de contar com o testemunho direto das mulheres. Assim, encontramos mulheres que escrevem, mas pouco ou nada sobre mulheres.

O mesmo silêncio sobre as mulheres e a condição feminina não é, contudo, regra entre os autores masculinos, como já ilustrámos, cons-

2 R. S. Kraemer "Becoming Christian" in Sh. James (2012) A Companion to Women in the Ancient World, 524-535, Wiley-Blackwel. 
tituindo o tema misógino um importante filão na literatura latina e literaturas vernáculas. Assim, trazemos aqui este interessante speculum feminarum medieval e sua tradução em Português.

I

Audite alfabetica

Cantica sophistica

Cuius sit amor generis

Et fauor muliebris.

II

Altum scolasticum

Sepe facit fantasticum

Feruens, fartum sceleris

Et opus prauitatis

III

Bilinguis mulier

Instabilis ut aer

Decipit quam plures,

Velut in nocte fures.

IV

Cruenta bestia,

Tendit ad terrestria,

Derisio, delusio

Status clericalis.

V

Dolosa Dalila,

Ad omne malum ualida,

Confusio, destructio

Fame personalis.

VI

Euam pronuntiat,

Viri fallatricem,

Cuius caue praesentiam

Velut damnatricem.
1

ouvi alfabéticos,

sábios cânticos

De como é o amor

da mulher, e o favor.

2

Ao ilustre doutor

Transforma em sonhador

Ardente, fértil no crime

E na obra da maldade

3

Bífida língua a mulher

Instável como o ar

Engana mais que milhões

Como na noite os ladrões

4

Cruenta fera

Atrai-a a terra

Decepção, desilusão

Do estado clerical

5

Dolosa Dalila

pronta para todo o mal

Confusão, destruição

Da fama pessoal.

6

Eva, denuncia-a

Do homem enganadora,

Teme dela a presença

Como se fosse destruidora. 
Furtiue subtrahit,

Foge à bailadeira,

Fugias saltatricem;

Que furtivamente semeia,

Mentis tue dementiam, na tua mente demência,

Agnosce meretricem.

Reconhece a alcoviteira.

VIII

8

Garrula et fatua,

Garganeira e enfatuada

Omnis honoris uacua,

De toda a honra esvaziada

Gerula mendacii,

Verborum comportatrix.

Da mentira mensageira

das conversas leva e traz .

IX

Habentem, non egentem

Facit mendicantem,

Dominum superbum

Transmutat in seruum.

$\mathrm{X}$

Ignis infernalis

Pena gehennalis,

Ira et inuidia

Per ipsa commituntur.

XI

Karitas deifica

Per ipsam obfuscatur;

Chaos creans malefica;

Desiste, amator.

XII

Lustrat per plateas

Pompas et choreas,

Visitat parochias,

Scholas et tabernas.

XIII

Mediatrix Mammone,

Miseri mechantis

Mors carnis et anime

Fit non penitentis.
9

Ao que tem, e nada precisa

Deixa-o sem uma miga

Ao senhor altivo

transforma em servo.

10

Infernal chama

Da Geena eterna pena

Ira e Inveja

Por ela se começam.

11

Caridade que deifica

Por ela está ofuscada

criadora do caos, maléfica

Desiste, alm' enamorada.

12

Lustrosa vai pelas praças,

Procissões e cantorias

Frequenta paróquias

Escolas e tabernas.

13

Mensageira de Mamon

ao luxurioso lazarento

A morte do corpo e da alma

É trazida sem lamento. 
XIV

Neutrum uult dimmitere,

Quemquam uult amare,

Clerum decipere

Et laicum defraudare.

XV

Omnes fallit homines, Papales, cardinales,

Monachos, presbiteros

Discordat prelatos.

XVI

Plures parit filios

Abs lege, facit spurios,

Quos uult esse heriles,

Seruos facit uiles.

XVII

Querit es et obolum

Grossum et florenum

Non querit honorem

Sed tendit ad pudorem.

XVIII

Rectrix senis, iuuenis,

Pauperis et diuitis,

Ipsa lutibundum

Totum facit mundum.

XIX

Sorbet sapientiam

Deglutit prudentiam,

Vt fecit Samsoni,

Platoni, Salomoni.

XX

Tondet tua, tenet sua

Torpet, torquet animum,

Friuolum, zelotypum,

Facit beniuolum.
14

Ninguém quer largar

Qualquer um quer amar

O clérigo enganar

o leigo defraudar.

15

Homens, a todos engana

Papas, cardeais

Monges e presbíteros

Divide os prelados.

16

Pare filhos aos milhares

Ilegítimos, faz bastardos

E aos que quer tornar herdeiros

transforma em servos vulgares.

17

Quer o asse e o óbolo

o grosso e o florim

Não quer a honra

Mas tende à vergonha.

18

Reitora do velho e do moço

Do pobre e do rico

Ela, num imenso atoleiro

Transforma o mundo inteiro.

19

Sorve a sabedoria

Devora a prudência

Tal como fez a Sansão

A Platão e a Salomão.

20

Tonsura o que é teu, segura o seu

Engana e tortura o espírito

Em frívolo e enciumado

Transforma o bem-intencionado. 
XXI

Vanitas, fatuitas,

Vanitatum vanitas

Honorem Deo demus

Et cum eo uiuemus.

XXII

Xristiani operibus,

Viro suo contraria,

Verbis et factis

Est nefaria.

XXIII

Yesi vendidit

Ecclesie sacramenta,

Sic ipsa rapuit

Honoris incrementa.

XXIV

Zelotypa et instabilis,

Fit sepe variabilis,
Propter tua munera

Ostenditur amabilis.
21

Vaidade, vanglória

Vaidade das vaidades

Honra a Deus demos

E com Ele viveremos.

22

Cristãs obras rejeita

para seu marido teimosa

Por palavras e gestos

É criminosa.

23

E da Igreja vendeu

de Jesus os sacramentos

Dessa forma roubou

Da virtude os incrementos.

24

Zelosa e instável

Frequentemente, inconstante só por causa dos teus bens Se apresenta amável.

Presumimos para este poema anónimo um destinatário masculino. Composto no séc. XIII, com vinte e quatro quadras, nem o número de sílabas, nem a rima, interna e externa, obedecem a um esquema constante, embora se detetem algumas regularidades.

Trata-se de um bom exemplo de poesia rítmica, (em que o acento de intensidade substitui a quantidade silábica como elemento definidor do código rítmico) o que é também uma forma literária caraterística da latinidade tardia. Este poema apresenta a particularidade de ser "alfabético", isto é, de cada estrofe, em vinte e quatro quadras, se iniciar segundo a letra da ordem alfabética, o que procurámos, pelo menos foneticamente (cf. o caso do $\underline{\mathrm{h}}$, do o e do $\underline{y}$ ), respeitar na tradução que aqui apresentamos.

Os poemas alfabéticos - em que os versos se iniciam segundo a ordem alfabética - e acrósticos - em que os versos se iniciam de modo 
a, verticalmente lidos os carateres iniciais, serem formadas palavras - correspondem a formas literárias de considerável sucesso na Idade Média, usadas em particular para temas de circunstância, destinadas a serem lidas, declamadas ou cantadas para impressionar o ouvinte pelo apuro formal. o caráter lúdico e ligeiro na interpretação e a simplicidade do discurso (frases curtas com predicados sintéticos verbo+objetos) atribuem a esta composição um propósito cómico, de riso fácil. Tal como hoje, no teatro de revista ou na stand up comedy, se busca a gargalhada imediata indo ao encontro do que são as crenças e os valores consolidados do destinatário, confirmando, portanto, o seu espaço de conforto.

Assim, encontramos neste texto de conteúdo misógino os lugares comuns da antiga e abundante temática clássica da diatribe contra as mulheres. Surgem, contudo, acusações novas e específicas, ligadas às vivências e à história do mundo medieval. Tema antigo, pois, mas em novas roupagens renovado.

O texto apresenta um esquema retórico previsível em relação ao gosto e às composições da época: em primeiro lugar, saliente-se a escolha das figuras de ornatus facilis: a paronomásia, "Dolosa Dalila”; “Tondet tua, tenet sua/torpet, torquet..."; "Derisio, delusio"; a aliteração "Mediatrix Mammone,/ Miseri mechantis"; a rima interna "Non querit honorem/ Sed tendit ad pudorem"; e externa, em esquema emparelhado AABB "Vanitas, fatuitas,/ Vanitatum vanitas/Honorem Deo demus/Et cum eo uiuemus" ; e cruzado ABAB "Yesi vendidit/ Ecclesie sacramenta,/ Sic ipsa rapuit/ Honoris incrementa", sendo estes dois os dominantes. A rima é, porventura, o mais destacado e mais inovador recurso formal nesta obra, se considerarmos que esta figura não era usada na poesia antiga. No entanto, a sua concretização reveste-se de grande liberdade associando por exemplo, rima interna e parassilabismo interestrófico (bilinguis// mulier/ instabilis// ut aer (3+2 sílabas); deglutit//prudentiam/Vt fecit// Samsoni (3+3 sílabas)

As figuras de palavras e de sentido, o ornatus difficilis, também se fazem presentes: a antítese, em particular, ao fazer oscilar o tópico 
da prodigalidade e da avareza; do cheio e do vazio, ou, dito por outras palavras, do exposto e do oculto: fatua/uacua (8); chaos creans (11); Querit/non querit/tendit (17); Tondet tua/tenet sua (20); uendidit/rapuit (23).

A expressividade do poema, contudo, não passa pela subtileza com que o conteúdo é exposto. Tudo são afirmações bombásticas, previsíveis, chavões generalistas. Do ponto de vista pragmático, no entanto, aplica-se uma fórmula que resulta: convencer pela repetição de conteúdos que vão ao encontro das expectativas do destinatário, simples de perceber, fáceis de memorizar. De médio fôlego, apresenta uma estrutura sintática paratática, e repetindo um esquema frásico muito simples, apoiado, em particular, na escolha dos adjetivos que caraterizam a mulher e dos verbos que descrevem as suas obras. Esta mulher aterradora faz (facit); transforma, torna (transmutat, fit); quer, não quer (querit/non querit; uult/non uult); engana, desilude e mente (fallit; decipere; defraudare). Instável, inconstante e vil, só se torna amável diante da fortuna dos homens. Este adjetivo, amabilis, expressivamente na última estrofe, é o único de sentido positivo utilizado para descrever a mulher. Mas esta sua qualidade não é permanente, pois só existe diante do grande propósito feminino: o dinheiro, os bens, a riqueza material. $\mathrm{Na}$ verdade, responde ao repto lançado na primeira estrofe, onde se formula a interrogação "de que tipo é o amor e o favor da mulher".

Surpreendente nos parece o fato de esta mulher não estar acompanhada de qualquer alusão às suas caraterísticas físicas, o que indicia o nível abstrato em que esta composição se situa e a distância estabelecida com a mulher real. Sendo uma composição anónima, o seu autor seria provavelmente alguém arredado do contacto com as mulheres, um clérigo ou um monge: é todo o género, e não uma mulher particular que é visada. Toda ela é ação insidiosa, que enleia a mente dos homens com as suas palavras e planos tortuosos.

Os verbos empregues são na sua maioria, predicadores dos seus atos. Excetuam-se os que se ligam ao vocativo, dirigidos aos destinatários 
do poema, ou seja, a todos os homens, instados a ouvir (audite) desde a primeira estrofe este catálogo de malfeitorias. Ao longo do poema este destinatário, converte-se num "tu" (tua; te, amator) mais informal: fugias; agnosce; desiste, que é instruído para se distanciar de semelhante criatura.

$\mathrm{O}$ apego às riquezas surge como a mais consistente acusação à mulher: mediadora de Mammon (13); gera filhos ilegítimos e, como os quer colocar como herdeiros, condena-os à servidão (16); quer o asse, o grosso, o florim, o óbolo. Esta referência a moedas de origens e cunhagens distintas aponta para o caráter universal da maldade feminina. É toda a mulher, qualquer que seja a sua proveniência, quem padece do vício da ganância e da corrupção material.

Como dissemos, a denúncia das maldades femininas é expressa por tópicos misóginos universais misturados com um ar fresco de novas e específicas acusações, formuladas para uma audiência que é, julgamos, essencialmente eclesiástica.

Por este poema passa o contexto histórico posterior à reforma da lei eclesiástica atribuída ao Papa Gregório VII (1073-1085). Esta teve como fim a afirmação da autoridade papal sobre a disciplina eclesiástica pela imposição de normas de uniformização e de moralização nos costumes do clero, reclamando a autoridade sobre as investiduras eclesiásticas. A divulgação das leis gregorianas foi feita em sínodos regionais, entre os bispos e os delegados papais, pelo que o conhecimento e os efeitos desta reforma se fizeram sentir ao longo do séc. XII.

A lenta e persistente revolução iniciada por Gregório, e continuada pelos papas que se lhe seguiram, sofreu oposição da aristocracia feudal que desde a Alta Idade Média condicionava as nomeações dos bispos, padres e abades das circunscrições eclesiásticas e mosteiros instalados nas suas propriedades. Conjugado com esta disciplina, a reforma gregoriana estabeleceu limites mais rígidos entre a profissão eclesiástica, seu carisma, interesses e funções; e os leigos. Neste sentido, combateu os antigos vícios da simonia, isto é o comércio dos sacramentos, dos lugares sagrados e das relíquias conduzido pelo clero, e o nicolaísmo, ou 
seja, a proximidade entre o clero e as mulheres, seja por concubinato, seja pela celebração de casamentos.

Em 1139, o II Concílio de Latrão reafirma a interdição do matrimónio para todo o clero, declarando nulos os casamentos existentes e forçando o clero que ainda vivesse em concubinato ou em casamento a uma mudança profunda de modo de vida. Subitamente, as suas mulheres e filhas deviam ser afastadas, escondidas (os filhos podiam sempre seguir a carreira eclesiástica ou o mosteiro). Não é, assim, um acaso o facto de estes terem sido os tempos do grande crescimento do monacato feminino. Esta determinação do celibato para o clero já fora estabelecida no I Concílio de Latrão (1123), tal como as diretivas de vários concílios da Igreja antiga e alto-medieval oscilavam entre a proibição do casamento para os bispos e sacerdotes e apenas a exortação ao celibato. Tratava-se de um desenvolvimento anunciado por sinais episódicos ao longo da história da Igreja, em particular da romana e latina, que vinha a estender até ao clero secular a disciplina da continência, da pobreza e da obediência próprias da vocação monástica.

Nos sécs. XI a séc. XIII, entre o clero e os monges letrados gera-se um movimento de alerta contra os males trazidos pela mulher. 0 imperativo legal da aplicação de reforma torná-lo-á mais consistente para um destinatário que pensamos resistir à continência, de outro modo não se entenderia o largo tempo e as dificuldades de aceitação da reforma, com a medida in extremis de declarar nulos os casamentos do clero no II Concílio de Latrão. Ou seja, a Igreja percebeu que os conselhos e exortações não bastavam para impor a continência e o celibato. Esta imposição legal significa que houve resistência às decisões anteriores. Assim, entre o séc. X e XIII, a literatura misógina torna-se mais agressiva do que até aî́ ${ }^{3}$ Não bastava proibir em concílios e nos cânones, era preciso sensibilizar, dissuadir e educar os pretendentes às ordens eclesiásticas,

3 Os mais significativos representantes da temática misógina Máximo de Turim PL 157, col.350; Geoffroy de Vendôme PL157, col.168; 126; Hildeberto de Lavardin PL 171, col. 1428; Marbordo de Rennes PL 171 col. 1698-99. 
diáconos, presbíteros e bispos, mas também os noviços e monges, para a rejeição do contacto com as mulheres, reforçando a perigosidade e a perversidade do género feminino. Assim, reforçam-se os tópicos antigos, atualizando-os com a realidade contemporânea dos ouvintes.

Esta mulher é a perdição para os sábios e cultos (estr. 2 scolasticum; 19 sorbet sapientiam/ ut fecit [...] Platoni, Salomoni ${ }^{4}$ ), de quem se quer apropriar do saber (19 sorbet sapientiam/deglutit prudentiam). É a perdição para o estado clerical de todas as hierarquias (4; 14 clerum decipere; 15 papales, cardinales/monachos presbiteros/discordat prelatos). A mulher é também um risco para os não consagrados (14 et laicum defraudare), para o marido (22 uiro suo contraria), para os homens em geral (14 omnes fallit homines - aqui numa expressiva assonância) seduzindo todas as idades (18 rectrix senis, iuuenis), de todas as classes, pobres e ricos (9 habentem [...] facit mendicantem/ dominum superbum/transmutat in seruum; 18 rectrix/[...] pauperis et diuitis).

Este motivo da apropriação do saber que é o apanágio do homem culto reitera-se pelo uso dos femininos de adjetivos de agente em -ix, normalmente raros, para descrever o espírito de iniciativa e papel ativo desta mulher. De claro cunho pejorativo, vejamos que alguns destes adjetivos, no masculino correspondente, são de qualidade neutra. Em suma, a mulher é perigosa porque é má, mas também porque se apropria de um agir entendido como masculino (e.g. 6, fallatrix, damnatrix; 7 saltatrix, meretrix; 8 comportatrix; 13 mediatrix; 17 rectrix).

Esta mulher não se recolhe em casa, como devia ser próprio do recato feminino, circulando pelo espaço público, seja profano ou religioso, com grande à vontade. Tal como no tópico anterior, da apropriação do saber dos homens cultos, ela apropria-se de um espaço exclusivo para os homens. Ou seja, estes atos tornam-se nefastos na medida em que são práticas transgressoras do género feminino (12 per plateas/ Pompas et choreas/ visitat parochias/scholas et tabernas.

4 São compreensíveis as referências a Dalila (5) e Sansão, tal como a Salomão. Acerca de Platão, contudo, não se encontra explicação, a não ser a do ajustamento à forma. 
O autor recorre também à evocação das vilãs da tradição bíblica, Dalila (5 dolosa Dalila) e Eva (6 Evam pronuntiat) $)^{5}$ que, só pelo nome, recuperam tipos femininos negativos conhecidos dos ouvintes.

Que conselhos o A. dá ao destinatário quanto ao modo de lidar com este ser nefasto? Foge dela (7 fugias saltatricem), ou seja, evita o confronto direto ou as ocasiões de tentação. Afinal, este canto evoca a maldade, o perigo, mas também a sedução e o poder das mulheres face a um homem débil, cuja única salvação é o não confronto, ou a fuga, posto que não consegue resistir. Pesa esta razão para o facto de apontarmos um destinatário eclesiástico para o poema, estes que eram instados a não se aproximarem das mulheres.

Perversa em vários domínios, salientemos as questões económicas e sociais, aquelas que nos parecem mais particularmente alusivas às circunstâncias dos tempos pós-gregorianos. Esta mulher é mensageira de Mamon (13 Mediatrix Mammone); gananciosa, quer dinheiro (17 querit e set obolum/grossum et florenum); é avara (20 tondet tua tenet sua); interesseira (9 habentem non egentem/ facit mendicantem). Todos estes atributos podem considerar-se dentro da tópica da avareza e ganância femininas. Mas ela divide os prelados (15). Ou seja, é causa de polémicas entre o clero. Pensamos que se trata de uma referência à questão difícil da continência e do celibato dos padres, muito discutida ao longo da aplicação da reforma gregoriana, e que suscitou oposição interna. Ou seja, as mulheres são fonte de discórdia entre o clero.

Esta mulher é, ainda, prolífica, dando à luz muitos filhos ilegítimos e bastardos. A acusação de nicolaísmo em que incorriam os padres incontinentes está na base deste argumento, posto que a geração de filhos expunha situações de casamentos não castos e de concubinatos. Assim, a declaração da nulidade dos matrimónios do clero trouxe consigo a ilegitimidade dos filhos destas uniões. Além da mácula social da bastardia e da ilegitimidade, acresce a fragilidade económica desta prole: uma vez

5 Jz. 16,. 16 Gen. 3. 
considerada irregular, os direitos à herança paterna seriam afetados. Por isso, esta mulher que, segundo o poema, de modo calculado gera filhos para que se tornem herdeiros, acaba por lhes legar a condição de servos vis, párias numa ordem social que os exclui.

A estrofe 22 é a de referência mais precisa ao tipo de fenómenos sociais combatido pela reforma gregoriana. É dito que a mulher vendeu os sacramentos de Jesus, isto é, trocou por dinheiro ou negociou bens simbólicos da Igreja que constituíam atribuições sacerdotais. Sendo um ataque preciso, pensamos que esta acusação remete para o pecado da simonia, em que se identificaram e se agiu contra eclesiásticos que vendiam os sacramentos, relíquias ou acesso a lugares sagrados, lucrando pessoalmente deste comércio de bens espirituais. Sendo este o facto aqui denunciado, há talvez o exagero de o imputar diretamente às mulheres. No entanto, uma das justificações para a realização deste comércio era a necessidade de sustentar umaa família natural, assim como uma das motivações para a reforma gregoriana foi a moralização do clero através da sua maior vinculação à hierarquia eclesiástica, libertando-o das obrigações familiares e dos compromissos do mundo.

Terminamos com uma referência à aplicação pedagógica e didática desta composição, no ensino dos níveis de Latim iniciação da Universidade e no ensino de Latim no Secundário.

Em primeiro lugar, o texto constitui um interessante documento ou ponto de partida para a exploração das considerações históricas e cívicas de uma problemática que radica na percepção dos géneros, assunto que merece destaque em qualquer plano de educação obrigatório, hoje bastante sensibilizado para o tema da igualdade entre os sexos. Abrir uma janela para o passado desta temática oferece uma abordagem real, não ideológica, da continuidade

Em segundo lugar, consideramos que determinados textos de Latim medieval se prestam bem à aprendizagem do Latim por estudantes de língua materna românica: é uma composição cuja simplicidade frásica 
permite que os estudantes se concentrem no estudo e na prática da morfologia (flexão nominal e verbal), bem como na aquisição de léxico. Os verbos e os adjetivos, de vários temas e classes, destacam-se pela frequência. Por outro lado, o exercício de tradução surge naturalmente, dada a ordem próxima das línguas românicas na disposição das partes do discurso (sj.+vb.+compl.); dada também a familiaridade com um vocabulário muito próximo do que existe nas línguas românicas, com transferência direta de sentido (afinal, trata-se de um texto de Latim Medieval, variante do Latim mais próxima dos seus descendentes românicos).

Em terceiro lugar, a exploração deste texto em aula de Latim para os níveis iniciantes proporciona o acesso a uma parte da aquisição da língua latina tantas vezes descurada, atendendo ao estereótipo que a fere, injustamente, (mas essa é outra questão!) de ser uma língua que não se ouve, nem se fala, e só se escreve: as questões de fonética e de fonologia. A pronúncia dos sons é fundamental, para a atualizaçãoda rima, das assonâncias, aliterações, paralelismos, e para tornar expressivo o facto de se tornar um poema alfabético. o facto de se tratar de um poema do séc. XIII não afeta o uso pedagógico do texto, posto que se verifica a sua adesão à norma clássica latina, como é próprio do ambiente culto e escolarizado em que foi produzido. Ateste-se, como exemplo, o facto de não haver diferenças fonéticas e fonológicas a registar, nesta atualização da língua, entre o V e o I consonânticos ou vocálicos em início de palavra (estrofes 10 e 21), o que pode proporcionar o esclarecimento sobre estes sons no latim, sua evolução e solução gráfica, com a invenção no renascimento das letras ramistas j e v paras assinalar o valor consonântico.

Acrescente-se ainda que, tratando-se de um texto medieval, os casos de sintaxe não violam a norma clássica, posto que se situam ao nível da parataxe, logo, da sintaxe básica das concordâncias; dos casos dos complementos verbais e das regências preposicionais. Em suma, tudo o que deve resultar no trabalho de um texto autêntico nos níveis iniciais do estudo da língua latina. 


\section{BIBLIOGRAFIA}

Bloch, R. Howard (1989), "Medieval Misogyny" Representations, 20, Special Issue: Misogyny, Misandry, and Misanthropy: 1-24.

Dalarun, J. (1991), "Regards de clercs", Duby, G., Perrot, Michelle Histoire des Femmes en Occident. II Le moyen Âge: 33-63.

Di Girolamo, Catia (2011), "A luta pela Investidura", Eco, Umberto coord. Idade Média II, ed. port. D. Quixote, 2013: 26-34.

L'Hermite - Leclercq (1990), “A ordem Feudal”, Duby, G. História das Mulheres, Afrontamento: 273- 329.

Norberg, Dag (1958), An introduction to Medieval Latin Versification, Catholic Uni versity of America press, 2004 (Jan Ziolkowski intr.).

Valerio, Adriana (2011), "El poder das mulheres", Eco, Umberto coord. Idade Média II, ed. port. D. Quixote, 2013: 220.

Wemple, S. (1990), “As mulheres do séc. V ao séc. X”, Duby, G. História das MuTheres, Afrontamento: 215-271. 